\title{
Removal of zinc ions from aqueous solution using micellar- enhanced ultrafiltration at low surfactant concentrations
}

\author{
Zhen Zhang ${ }^{1}$, Guang-Ming Zeng ${ }^{1 *}$, Jin-Hui Huang', Yao-Yao Fang', Ke Xu', \\ Yun-Huan $\mathbf{Q u}^{1}$, Chun-Ping Yang ${ }^{1}$ and Jian-Bing $\mathrm{Li}^{2}$ \\ ${ }^{1}$ College of Environmental Science and Engineering, Hunan University, Changsha 410082, China \\ ${ }^{2}$ Canada-China Center of Energy and Environment Research, University of Regina, Regina,SK S4S OA2, Canada
}

\begin{abstract}
Micellar-enhanced ultrafiltration (MEUF) of zinc ions $\left(\mathrm{Zn}^{2+}\right)$ from aqueous solutions using single anionic surfactant sodium dodecyl sulphate (SDS) at low critical micelle concentrations $(\mathrm{cmc})(0.2 \times \mathrm{cmc}-3 \times \mathrm{cmc})$ was investigated. When the initial SDS concentration was below the cmc, unexpectedly high rejection $(97.5 \%)$ was obtained due to concentration polarisation occurring near the membrane-solution interface. Based on this mechanism, the true rejection of the solute is no longer a function of the initial SDS concentration in the bulk solution but a function of the SDS concentration at the concentration polarisation layer. The removal of $\mathrm{Zn}^{2+}$ at low $\mathrm{Zn}^{2+}$ feed concentrations was very efficient. The characteristics of $\mathrm{Zn}^{2+}$ ion adsorption to surfactant micelle were also studied. The Langmuir model could be used to elucidate the $\mathrm{Zn}^{2+}$ adsorption isotherm to the SDS micelle. The study demonstrates the potential practicality of the MEUF technique for the removal of heavy metal ion pollutants such as $\mathrm{Zn}^{2+}$ at low surfactant concentrations.
\end{abstract}

Keywords: micellar-enhanced ultrafiltration, concentration polarisation, sodium dodecyl sulphate, micelle, Langmuir isotherm

\section{List of symbols}

$R \quad$ percent rejection (\%)

C concentration of the $\mathrm{Zn}^{2+}(\mathrm{mg} / \ell)$

$J \quad$ permeate flux $\left(\mathrm{m}^{3} / \mathrm{m}^{2} \cdot \mathrm{s}\right)$

$\Delta p \quad$ trans-membrane pressure $(\mathrm{Pa})$

$R_{\mathrm{m}} \quad$ hydraulic resistance of membrane $\left(\mathrm{m}^{-1}\right)$

$R_{\mathrm{f}} \quad$ secondary resistance of the membrane $\left(\mathrm{m}^{-1}\right)$

$\mu \quad$ viscosity coefficient (Pa.s)

$\alpha \quad$ volume concentrated ratio

$\beta \quad$ concentration concentrated ratio

$\mathrm{V} \quad$ volume $(\ell)$

$K \quad$ adsorption equilibrium constant $(\ell / \mathrm{mmol})$

$q_{\max } \quad$ maximum amount of adsorbed $\mathrm{Zn}^{2+}(\mathrm{mmol} / \mathrm{g})$

$q_{\mathrm{e}} \quad$ amount of adsorbed $\mathrm{Zn}^{2+}$ at equilibrium $(\mathrm{mmol} / \mathrm{g})$

$\mathrm{C}_{\mathrm{e}} \quad$ concentration of $\mathrm{Zn}^{2+}$ in the bulk liquid phase at equilibrium $(\mathrm{mmol} / \ell)$

\section{Subscripts}

initial feed solution

permeate

retentate

water

solution

\section{Introduction}

Heavy metal water pollution is a serious environmental problem in the world. The metal ions are non-biodegradable, highly toxic

\footnotetext{
* To whom all correspondence should be addressed.

证 +86-731-8822754; fax: +86-731-8823701;

e-mail: zgming@,hnu.cn

Received 24 April 2006; accepted in revised form 29 October 2006.
}

and may have a potentially carcinogenic effect. If directly discharged into the sewage system, they may seriously damage the operation of biological treatment plants. Wastewater containing dissolved metal ions such as zinc, cadmium, nickel and copper originate from a variety of sources such as metal mine-tailing leachate, refineries, semi-conductor manufacturing, battery, abandoned metal mines and metal plating industries. At present, the traditional techniques for the removal of metal ions from wastewater that are in practice include adsorption, extraction, precipitation, electrolytic method, ion exchange method, and distillation. However, these techniques have their own disadvantages, such as inconvenient operation, secondary pollution of deposition, loss of expensive chemicals, difficulty in recovering metal ion, strong $\mathrm{pH}$ sensitivity, incapable of reducing metal ions concentration to the levels required by law and so on.

Micellar-enhanced ultrafiltration (MEUF) as a surfactantbased separation process is an effective technique to remove almost all the toxic metal ions and/or soluble organic solutes from aqueous solutions (Baek et al., 2003; 2004; Gzara et al., 2001; 2000; Juang et al., 2003; Kim et al., 2003; Liu et al., 2004; Tung et al., 2002; Yurlova et al., 2002). In the MEUF process, the surfactant is added to the polluted aqueous solution containing metal ions and/or organic solutes. The surfactant forms micelles which are charged spherical aggregates containing 50 to 150 surfactant molecules at a concentration higher than its critical micelle concentration $(\mathrm{cmc})$ and above its Kraft point temperature (Gzara and Dhahbi, 2001). The metal ions are adsorbed on the surface of the oppositely charged micelles by electrostatic attraction. The organic solutes are solubilised in the micelles interior by ion-dipole interaction. Then the micellar solution passes through an ultrafiltration membrane with a small enough pore size to reject the micelles containing the contaminants. As micelles are rejected, the adsorbed metal ions and the solubilised organic solutes will also be rejected. The un-adsorbed metal ions or un-solubilised organic solutes and surfactant monomers 


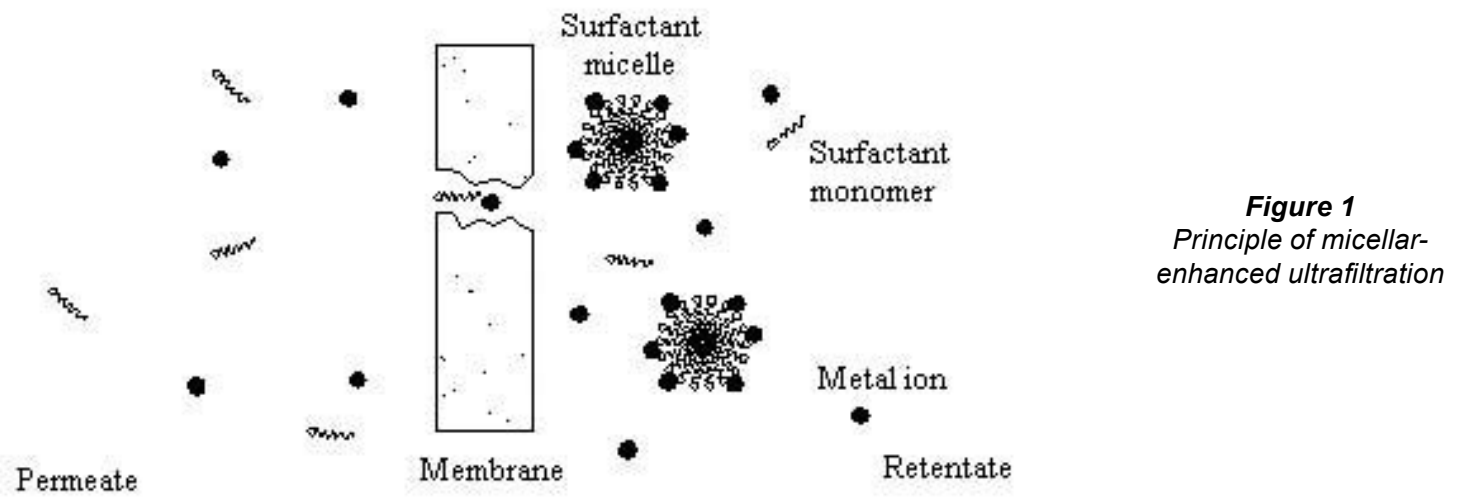

pass through the ultrafiltration membrane to the permeate side. As a result, the permeate will contain very low concentrations of un-adsorbed metal ions or un-solubilised organic solutes and surfactant monomers, resulting in a clean permeate which can be recycled or discarded. The retentate solution is much more concentrated and considerably lower in volume than the initial solution; therefore, the further treatment or disposal of the smaller amount of solution is less expensive and much easier, such as recovering the surfactant and metal ion. The principle is shown in Fig. 1 (Sadaoui et al., 1998). This method has the following advantages: simple operation; environmentally safer; low-energy requirement; high removal efficiency; easy to recover metal ions; less expensive; separation can be carried out at room temperature; the modular membrane surface can be easily adjusted to the wastewater flows; and various industrial membranes are now available.

Since the MEUF technique was proposed, there have been a number of studies in the wastewater treatment field. However, at present the study of the MEUF technique is still at a laboratory-scale stage. Many studies were mostly carried out in batch stirred cells using lamellar membranes at surfactant concentrations much higher than the cmc (Baek et al., 2003; Gzara et al., 2000; 2001; Juang et al., 2003). In these studies, the permeate fluxes of ultrafiltration membranes were very low when using lamellar membranes and very high concentration surfactants. Since the concentrations of surfactants were much higher than the cmc, large quantities of surfactants must be used for the separation and therefore the concentrations of surfactants in the retentate were very high. Consequently, the economic viability of the MEUF process will strongly depend on the ability to recover a large portion of the surfactant from the retentate. Clearly, this may increase the cost of the separation process. On the other hand, the surfactant monomers inevitably leaked into the permeate through the ultrafiltration membrane and produced secondary pollution. To overcome the deficiencies mentioned above, some studies were conducted using mixed anionic-non-ionic surfactants (Aoudia et al., 2003; Fillipi et al., 1999). Aoudia et al. (2003) reported that $\mathrm{Cr}^{3+}$ rejection (99\%) was obtained at total surfactant mixtures (SDS-nonylphenol ethoxylated) concentration of $3 \times \mathrm{cmc}$. But the total surfactant mixtures concentration $(3 \times \mathrm{cmc})$ is comparatively high. The mixed anionic-non-ionic surfactant system is not very effective for reducing the dosage of surfactant. Using non-ionic surfactant also makes the recovery of surfactant more difficult in these studies. Considering the factors discussed above, there is an apparent need to achieve efficient solute rejection using a single surfactant at relatively low concentration. It will reduce the dosage of the surfactant and the surfactant concentration in the retentate markedly, thereby reducing the expense of the process. Also, it will reduce the sur- factant concentration in the permeate and improve the permeate flux of the ultrafiltration membrane. When the surfactant concentration is low, the efficient solute rejection is not expected in principle, but the concentration polarisation effect can assist in achieving such aims at low-concentration surfactant. Some level of concentration polarisation may have a beneficial effect in terms of permeate rejection.

On the other hand, previous studies on the removal of metal ions using the MEUF technique were mainly based on the rejection of metal ions and the permeate flux. The characteristics of metal ion adsorption to surfactant micelle have been scarcely investigated (Ahmadi et al., 1995; Li et al., 2006). However, the adsorption characteristics are the key factors for the successful application of MEUF.

In the present study, an attempt is made to remove $\mathrm{Zn}^{2+}$ ions from aqueous solutions by MEUF using single anionic surfactant sodium dodecyl sulphate (SDS) at low concentrations in order to reduce the expense of the process and the secondary pollution. The modified polysulphone hollow-core fibre ultrafiltration membrane is used in the study. The hollow-core fibre UF device is operated in linear continuous and cross-flow mode which has much higher flux and much more effective membrane area than the conventional batch-cell system using a lamellar membrane. The effects of parameters such as the initial surfactant SDS concentration $(0.2 \times \mathrm{cmc}$ to $3 \times \mathrm{cmc})$, and the initial pollutant $\mathrm{Zn}^{2+}$ ion concentration $(20 \mathrm{mg} / \ell$ to $300 \mathrm{mg} / \ell)$ on the efficiency of $\mathrm{Zn}^{2+}$ ion rejection and the permeate flux will be investigated. The characteristics of $\mathrm{Zn}^{2+}$ ion adsorption to surfactant micelle will also be examined. The adsorption isotherm model of $\mathrm{Zn}^{2+}$ ion adsorption to surfactant micelle will be established to investigate the mechanism of $\mathrm{Zn}^{2+}$ adsorption to the SDS micelle. These results will be helpful to realise the practical application of this technique.

\section{Experimental}

\section{Materials}

The SDS used in this research was obtained from Tianjin Kermel Chemical Reagents Development Center. Its molecular formula is $\mathrm{CH}_{3}\left(\mathrm{CH}_{2}\right)_{10} \mathrm{CH}_{2} \mathrm{OSO}_{3}$ with a molecular weight of 288.38 , and a purity of $99 \%$. Zinc nitrate hexahydrate was obtained from Shanghai Tinxin Chemical Reagent Plant. Its molecular formula is $\mathrm{Zn}\left(\mathrm{NO}_{3}\right)_{2} \cdot 6 \mathrm{H}_{2} \mathrm{O}$ with a molecular weight of 297.49 , and purity of $99 \%$. Nitric acid, sodium hydroxide and sodium hypochlorite were purchased from Shanghai Chemical Reagent Limited Company, in AR grade. The feed solutions were prepared by dissolving different amounts of SDS and zinc nitrate hexahydrate in deionised water. The deionised water was produced by 
Figure 2

Schematic of micellarenhanced ultrafiltration process

1: Feed solution;

2: Thermostat;

3: Peristaltic pump;

4: Membrane module;

5: Permeate;

6: Retentate;

7: Pressure control valve;

8: Manometer;

9, 10: Rotameter

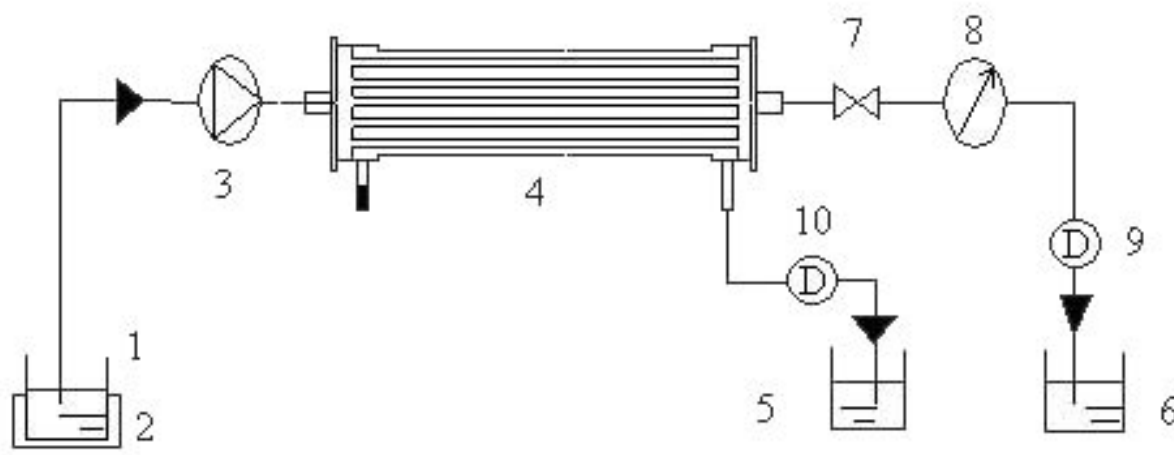

6

a laboratory water purification apparatus (Labconco, USA) with an initial resistivity of $18.2 \mathrm{M} \Omega \cdot \mathrm{cm}$. The ultrafiltration membrane used in the research was a hollow-core fibre ultrafiltration membrane produced by Tianjin Motianmo Co. (China) of the type UEOS503. The characteristics of the membrane are shown in Table 1.

\section{Procedure}

Micellar-enhanced ultrafiltration experiments were performed at room temperature. The procedure is shown in Fig. 2. The feed tank was initially filled with $10 \ell$ of feed solution. The solution temperature was held constant at $30^{\circ} \mathrm{C}$ using a thermostat to avoid any precipitation because the Kraft point of the SDS is $14^{\circ} \mathrm{C}$. The solution $\mathrm{pH}$ was not adjusted. After being fully mixed, the solution was fed into the membrane module for linear continuous ultrafiltration by Peristaltic pump at a constant pressure of $0.07 \mathrm{MPa}$. At the desired time intervals, the permeate was sampled. The used membrane was immediately flushed at room temperature for $15 \mathrm{~min}$ at $0.03 \mathrm{MPa}$ using deionised water, 0.01 $\mathrm{M} \mathrm{HNO}_{3}, 0.1 \mathrm{M} \mathrm{NaOH}, 1 \% \mathrm{NaClO}$. After each step in the cleaning procedure, deionised water was circulated at $0.03 \mathrm{MPa}$ and room temperature, until the $\mathrm{pH}$ of the permeate became neutral. When maintained as described above, the membrane exhibited a constant initial permeate flux after daily use.

The deionised water permeate flux and solution permeate flux of the ultrafiltration membrane were measured by the rotameter at constant trans-membrane pressures.

\section{Analysis}

The SDS concentration was determined by the methylene blue spectrophotometric method with Shimadzu UV-2550 (P/N206$55501-93$ ) spectrophotometer at $652 \mathrm{~nm}$. The $\mathrm{Zn}^{2+}$ ion concentration was analysed by atomic absorption spectrometry (Perkin Elmer, Modle AAnalyst 700) at $213.8 \mathrm{~nm}$.

\section{Results and discussions}

\section{Effect of SDS concentration}

Effect of the SDS concentration on the rejection of $\mathrm{Zn}^{2+}$ To evaluate the filtration efficiency in removing the $\mathrm{Zn}^{2+}$ from the feed solution, we used the rejection rate $R$ expressed as:

$$
\begin{aligned}
& R=\frac{C_{\mathrm{i}}-C_{\mathrm{p}}}{C_{\mathrm{i}}} \times 100 \% \\
& \text { where: } \\
& C_{\mathrm{i}} \text { is the initial concentration of the } \mathrm{Zn}^{2+}(\mathrm{mg} / \ell) \text { in the feed } \\
& \text { solution } \\
& C_{\mathrm{p}} \text { is the concentration of the } \mathrm{Zn}^{2+}(\mathrm{mg} / \ell) \text { in the permeate. }
\end{aligned}
$$

Figure 3 shows the variation of the $\mathrm{Zn}^{2+}$ rejection with the initial SDS concentrations ranging from $0.2 \times \mathrm{cmc}(1.56 \mathrm{mmol} / \ell)$ up to $3 \times \mathrm{cmc}(23.4 \mathrm{mmol} / \ell)$ at a constant $\mathrm{Zn}^{2+}$ concentration of 50 $\mathrm{mg} / \ell$ and a constant pressure of $0.07 \mathrm{MPa}$. The critical micelle concentration of SDS $(7.8 \mathrm{mmol} / \ell)$ was obtained by conductivity measurement (not shown). The rejection of $\mathrm{Zn}^{2+}$ increased with the initial concentration of SDS. As observed from the figure the rejection of $\mathrm{Zn}^{2+}$ increased from $38.6 \%$ to $97.5 \%$, when the initial concentration of SDS grew from $0.2 \times \mathrm{cmc}$ to $0.8 \times$ cmc. When the SDS concentration is below its $\mathrm{cmc}$, no micelles are present in the bulk solution in theory and no rejection of $\mathrm{Zn}^{2+}$ is expected. The rejection could be primarily attributed to the concentration polarisation. The concentration polarisation is an important characteristic of all ultrafiltration systems. It is caused by the accumulation of retained solutes or particles on the membrane surface. Some level of concentration polarisation may have a beneficial effect in terms of permeate rejection. The increased concentration of the solute in the vicinity of the membrane surface has been shown to act as a 'secondary' membrane and aids in rejecting solutes. As the initial SDS concentration is below the cmc, all the surfactant molecules are in the form of free monomers, the size of which is much smaller than the pore diameter of the membrane. Under these conditions, monomers should easily cross the membrane, and yet the surfactant is partly retained. The surfactant monomer is impeded as it passes through the membrane into the permeate since the permeate concentration is lower than the $\mathrm{cmc}$; this retardation may be caused by charge or steric effects (Gzara and Dhahbi, 2001). The SDS concentration being rejected by the membrane becomes higher in the region of the retentate solution adjacent to the membrane surface than the bulk solution. This region is called the concentration polarisation layer. When the SDS concentration reaches $\mathrm{cmc}$ level at the concentration polarisation layer, many SDS monomers begin to form large numbers of big-size micelles at the concentration polarisation layer. These micelles provide more adsorption sites for the $\mathrm{Zn}^{2+}$ in the initial feed solution and reduce the fraction of $\mathrm{Zn}^{2+}$ passing through

\begin{tabular}{|c|c|c|c|c|c|c|}
\hline \multicolumn{7}{|c|}{ TABLE 1 } \\
\hline $\begin{array}{c}\text { Characteristics of the used membrane } \\
\mathbf{\Phi} \times \mathbf{\ell}(\mathrm{mm})\end{array}$ & $\begin{array}{c}\text { Molecular weight } \\
\text { cut-off (Dalton) }\end{array}$ & $\begin{array}{c}\text { Area of } \\
\text { membrane } \\
\left(\mathbf{m}^{2}\right)\end{array}$ & $\mathrm{pH}$ & $\begin{array}{c}\text { Membrane } \\
\text { material }\end{array}$ & $\begin{array}{c}\text { Inner/outer } \\
\text { diameter of } \\
\text { fiber }(\mathrm{mm})\end{array}$ & $\begin{array}{c}\text { Trans-membrane } \\
\text { pressure } \\
(\mathrm{MPa})\end{array}$ \\
\hline $50 \times 386$ & $6 \mathrm{~K}$ & 1.5 & $2-13$ & Modified -PS & $0.24 / 0.4$ & $\leq 0.15$ \\
\hline
\end{tabular}




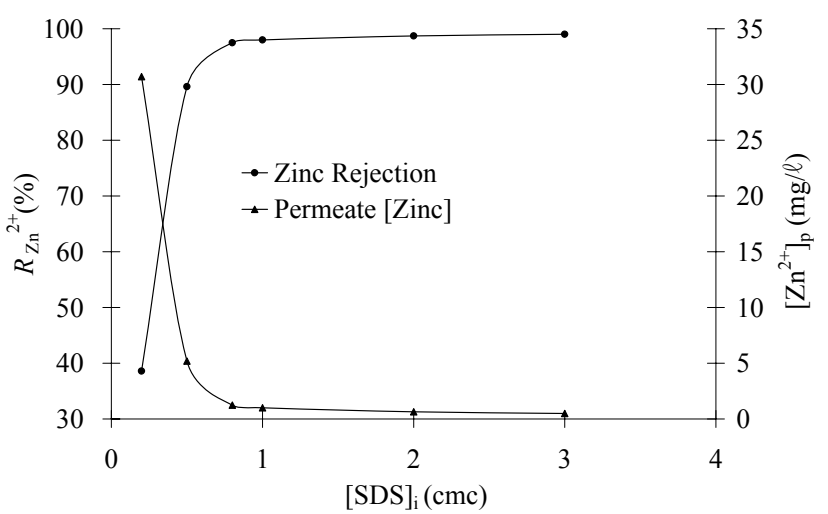

Figure 3

Effect of the initial SDS concentration on the rejection of $\mathrm{Zn}^{2+}$ and the permeate $\mathrm{Zn}^{2+}$ concentration. $\left[\mathrm{Zn}^{2+}\right]_{i}=50 \mathrm{mg} / \mathrm{\ell}, \Delta P=0.07$ $\mathrm{MPa}, \mathrm{T}=30^{\circ} \mathrm{C}$

the membrane to the permeate side. Furthermore, an increase in the initial SDS concentration may also result in higher concentration polarisation (much larger number and larger size of micelles) at the concentration polarisation layer. Therefore, the rejection of $\mathrm{Zn}^{2+}$ increased rapidly when the initial concentration of SDS grew from $0.2 \times \mathrm{cmc}$ to $0.8 \times \mathrm{cmc}$.

As the SDS concentration exceeded its $\mathrm{cmc}$, the rejection variations were small (98\% to 99\%). Aoudia et al. (2003) reported that the $\mathrm{Cr}^{3+}$ rejections (99\%) were obtained at total surfactant (SDS-nonylphenol ethoxylated) concentrations of $3 \times \mathrm{cmc}$ and $30 \times \mathrm{cmc}$. Interestingly, this rejection (above the SDS's cmc) is practically independent of surfactant concentration at a constant metal ion concentration, strongly suggesting concentration polarisation as the obvious mechanism. In terms of this mechanism, the true rejection of the solute is no longer a function of the initial SDS concentration in the bulk solution but a function of the SDS concentration at the concentration polarisation layer when the solute concentration remains constant. Also, at the initial SDS concentration of $0.8 \times \mathrm{cmc}$ and $3 \times \mathrm{cmc}$, the rejections were $97.5 \%$ and $99 \%$, respectively (Fig. 3). Thus, some level of concentration polarisation is a valuable practical aspect of the MEUF process, in terms of the low surfactant concentration required to achieve high solute rejections.

The economic viability of the MEUF process is strongly dependent on the ability to recover the surfactant, still a challenging task. Therefore, using a low-surfactant concentration system is highly desirable in order to reduce surfactant usage and surfactant loss. The concentration polarisation effect may assist in achieving such aims. When the initial SDS concentration was equal to $0.8 \times \mathrm{cmc}$, not only high $\mathrm{Zn}^{2+}$ rejection $(97.5 \%)$ could be obtained but the permeate flux was also comparatively high (shown in Fig.3). Therefore, the initial surfactant SDS concentration of $0.8 \times \mathrm{cmc}$ is the appropriate value to obtain effective treatment effect at low surfactant concentration.

\section{Effect of the SDS concentration on the permeate flux and the secondary resistance}

However, in spite of the many advantages of ultrafiltration process, flux decline is still the most serious and inherent obstacle for the efficient application of the MEUF process. Therefore, not only the separation efficiency of metal ions and the optimisation of process variables but also the flux behaviours in micellarenhanced ultrafiltration should be investigated systematically.

The resistance of the ultrafiltration membrane in micellar- enhanced ultrafiltration includes the hydraulic resistance of the membrane and the secondary resistance which is caused by the fouling of the membrane. They are expressed as:

$$
\begin{aligned}
& R_{\mathrm{m}}=\frac{\Delta P}{\mu_{\mathrm{w}} \times J_{\mathrm{w}}} \\
& R_{\mathrm{f}}=\frac{\Delta P}{\mu_{\mathrm{s}} \times J_{\mathrm{s}}}-R_{\mathrm{m}}
\end{aligned}
$$

where:

$R_{\mathrm{m}}$ is the hydraulic resistance of membrane $\left(\mathrm{m}^{-1}\right)$

$R_{\mathrm{f}}$ is the secondary resistance of the membrane $\left(\mathrm{m}^{-1}\right)$

$\mu_{\mathrm{w}}$ is the viscosity coefficient of water ( $\left.\mathrm{Pa} \cdot \mathrm{s}\right)$

$\mu_{\mathrm{s}}$ is the viscosity coefficient of solution $(\mathrm{Pa} \cdot \mathrm{s}) ; J_{\mathrm{w}}$ is the permeate flux of water $\left(\mathrm{m}^{3} / \mathrm{m}^{2} \cdot \mathrm{s}\right)$

$J_{\mathrm{s}}$ is the permeate flux of solution $\left(\mathrm{m}^{3} / \mathrm{m}^{2} \cdot \mathrm{s}\right)$

The general relationship between the solution permeate flux and total resistance is given by the following equation:

$$
J_{\mathrm{p}}=\frac{\Delta P}{u_{\mathrm{s}}\left(R_{\mathrm{m}}+R_{\mathrm{f}}\right)}
$$

In the study, the modified polysulphone hollow-core fibre ultrafiltration membrane was used. The deionised water permeate flux of the membrane $\left(20 \mathrm{l} / \mathrm{m}^{2} \cdot \mathrm{h}\right)$ is much higher than that of the lamellar membrane $\left(2.31 \mathrm{l} / \mathrm{m}^{2} \cdot \mathrm{h}\right)$ reported by Juang et al. (2003). This indicates that the hollow-core fibre ultrafiltration membrane is much better than the lamellar membrane.

The study of the permeate flux variation according to the initial SDS concentration $(0.2 \times \mathrm{cmc}$ to $3 \times \mathrm{cmc})$ in the feed solution (Fig. 4) reveals that the permeate flux decreased with the increase of the initial SDS concentration as the ultrafiltration progressed, and the secondary resistance increased with the increase of the initial SDS concentration. As shown in Fig. 4, the permeate flux decreased to $50 \%$ of the flux of deionised water when the initial SDS concentration was equal to $3 \times \mathrm{cmc}$. The viscosity coefficient of solution $\mu_{\mathrm{s}}$ increased very slightly with the increase of the initial SDS concentration (not shown), so it could be neglected in the experiment. The reduction in the permeate flux can be attributed to the concentration polarisation explained above. Although no micelles are present in the initial feed solution at the initial SDS concentration below the cmc, a larger fraction of surfactants is present in the micellar form in the vicinity of the membrane surface. The micelles accumulate on the membrane surface continually and some small micelles block the membrane pores. Further, an increase in the initial SDS concentration may also result in higher concentration polarisation at the concentration polarisation layer. Therefore, higher secondary resistance of the membrane increased and the permeate flux decreased synchronously. Similarly in the same way, when the initial SDS concentration was higher than the $\mathrm{cmc}$, the permeate flux through the membrane decreased due to a large increase in the secondary resistance to flow caused by the concentration polarisation.

Though the permeate flux decreased with the increase of the initial SDS concentration due to the concentration polarisation, the permeate flux of $13.2 \mathrm{l} / \mathrm{m}^{2} \cdot \mathrm{h}$ was comparatively high when the initial SDS concentration was equal to $0.8 \times \mathrm{cmc}$. It indicates good potential practical application of the MEUF technique using the hollow-core fibre ultrafiltration membrane to remove metal ions from wastewater at low surfactant concentration. 


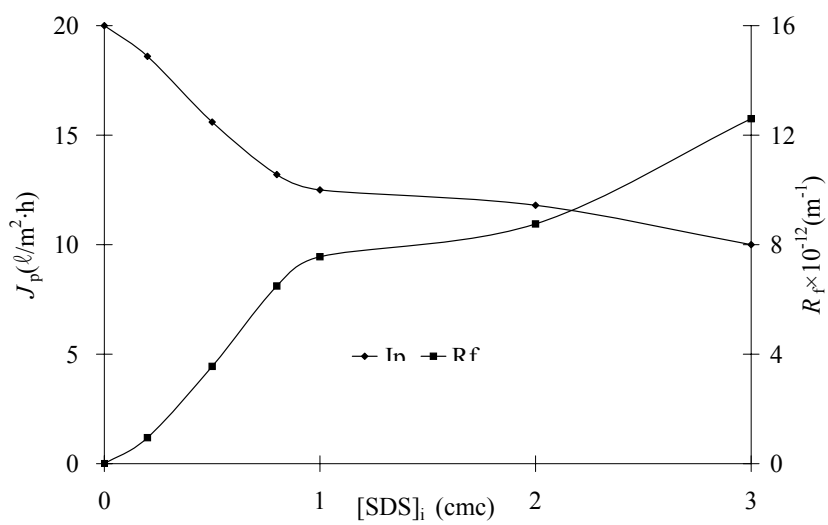

Figure 4

Effect of the initial SDS concentration on the permeate flux and the secondary resistance. $\left[\mathrm{Zn}^{2+}\right]_{i}=50 \mathrm{mg} / \mathrm{l}, \Delta P=0.07$ $\mathrm{MPa}, \mathrm{T}=30^{\circ} \mathrm{C}$

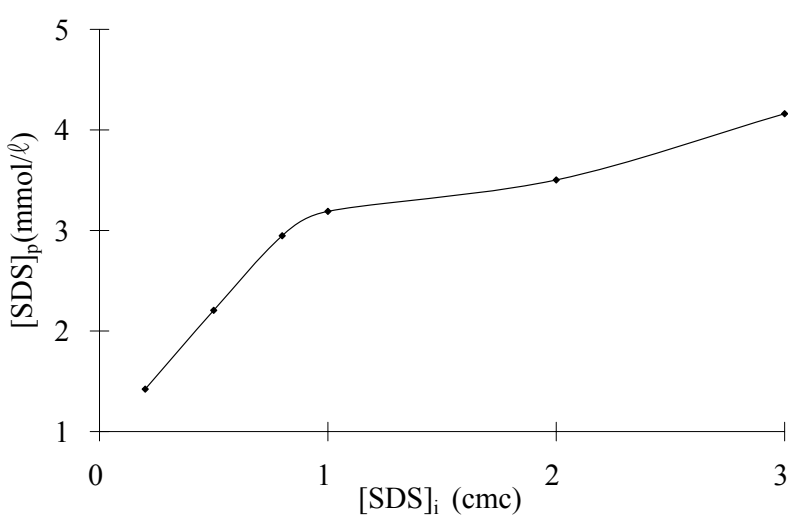

Figure 5

Effect of the initial $S D S$ concentration on the permeate $S D S$ concentration. $\left[\mathrm{Zn}^{2+}\right]_{i}=50 \mathrm{mg} / \ell, \Delta P=0.07 \mathrm{MPa}, T=30^{\circ} \mathrm{C}$

\section{Effect of the SDS concentration on the permeate SDS concentration}

The permeate SDS concentration should be considered to evaluate the performance of the MEUF process because the surfactant in the permeate may induce a secondary pollution.

The variation in permeate SDS concentration as against the different initial SDS concentrations $(0.2 \times \mathrm{cmc}$ to $3 \times \mathrm{cmc})$ in the feed solution is described in Fig. 5. The experimental results were depicted at a constant pressure of $0.07 \mathrm{MPa}$. As observed from the figure, the permeate SDS concentration increased with the increase of the initial SDS concentration.When the initial SDS concentration was below the $\mathrm{cmc}(0.8 \times \mathrm{cmc})$, almost $53 \%$ surfactant rejection was reached. As the size of surfactant monomers is much smaller than the membrane pore size, the monomers can easily pass through the membrane in principle. The rejection can be attributed to the concentration polarisation explained above and the adsorption of surfactant at the membrane surface. Then, when the initial SDS concentration was higher than the cmc, the permeate SDS concentration increased with the initial SDS concentration and did not exceed the cmc value (when the initial SDS concentration increased to $3 \times \mathrm{cmc}$, the SDS permeate concentration was equal to $4.2 \mathrm{mmol} / \ell$ ). Whatever the concentration of surfactant in the feed is, the surfactant concentration in the permeate is lower than the cmc (Gzara and Dhahbi, 2001). Consequently the loss of the surfactant SDS and the secondary pollution by SDS is weak.

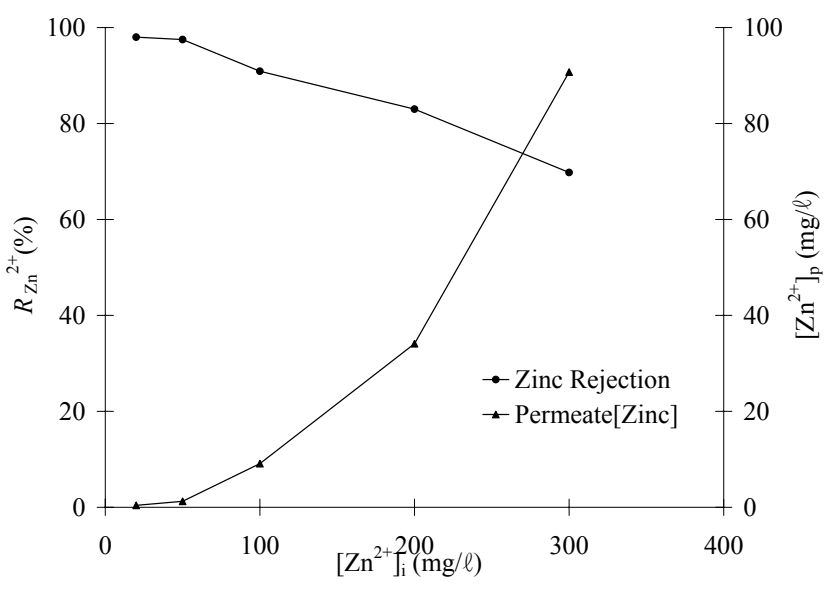

Figure 6

Effect of the initial SDS concentration on the volume concentrated ratio and the concentration concentrated ratio. $\left[\mathrm{Zn}^{2+}\right]_{i}=50 \mathrm{mg} / \ell, \Delta P=0.07 \mathrm{MPa}, T=30^{\circ} \mathrm{C}$

\section{Effect of the SDS concentration on the volume concentrated ratio and the concentration concentrated ratio}

The volume concentrated ratio $\alpha$ and the concentration concentrated ratio $\beta$ are also used in our experiment to evaluate the ultrafiltration efficiency. They are expressed as:

$$
\begin{gathered}
\alpha=\frac{V_{\mathrm{i}}}{V_{\mathrm{r}}} \\
\beta=\frac{C_{\mathrm{r}}}{C_{\mathrm{i}}}
\end{gathered}
$$

where:

$V_{\mathrm{i}}$ is the initial volume of the feed solution $(\ell)$

$V_{\mathrm{r}}$ is the volume of the retentate solution $(\ell)$

$C_{\mathrm{i}}$ is the initial concentration of the $\mathrm{Zn}^{2+}(\mathrm{mg} / \ell)$ in the feed solution

$C_{\mathrm{r}}$ is the concentration of the $\mathrm{Zn}^{2+}(\mathrm{mg} / \ell)$ in the retentate.

Figure 6 shows the variation of the volume-concentrated ratio and the concentration- concentrated ratio with the initial SDS concentration ranging from $0.2 \times \mathrm{cmc}$ up to $3 \times \mathrm{cmc}$ at the initial $\mathrm{Zn}^{2+}$ concentration of $50 \mathrm{mg} / \ell$ and a constant pressure of $0.07 \mathrm{MPa}$. Along with the increase of the initial SDS concentration, the volume-concentrated ratio decreased gradually. The concentration-concentrated ratio increased when the initial SDS concentration grew from $0.2 \times \mathrm{cmc}$ to $0.8 \times \mathrm{cmc}$. When the initial SDS concentration was equal to $0.8 \times \mathrm{cmc}$, the maximum concentration-concentrated ratio was obtained. Beyond the concentration, the concentration-concentrated ratio decreased gradually probably due to the increase of the retentate volume. The high volume-concentrated ratio and concentration- concentrated ratio not only reflect better efficiency of MEUF but are also propitious to recover surfactant and metal ion from the retentate by some methods, such as chemical precipitation (Juang et al., 2003), electrolytic method (Liu and Li, 2004) and so on. Recovery of surfactant and metal ion for reuse makes the MEUF process more economical and safer.

\section{Effect of $\mathrm{Zn}^{2+}$ concentration}

Effect of the $\mathrm{Zn}^{2+}$ concentration on the rejection of $\mathrm{Zn}^{2+}$ The effect of varying the initial $\mathrm{Zn}^{2+}$ concentration on the $\mathrm{Zn}^{2+}$ 


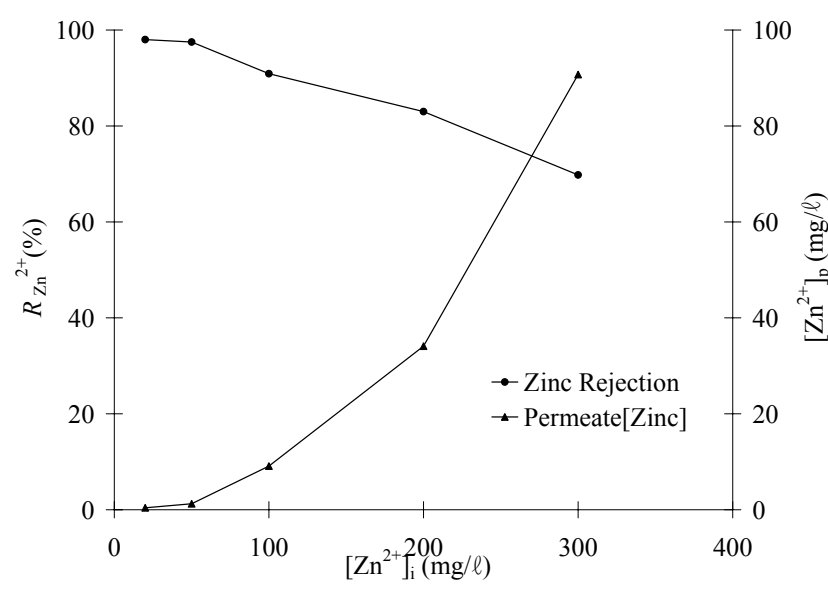

Figure 7

Effect of the initial $\mathrm{Zn}^{2+}$ concentration on the rejection of $\mathrm{Zn}^{2+}$. $[S D S]_{i}=0.8 \times \mathrm{Cmc}, \Delta P=0.07 \mathrm{MPa}, T=30^{\circ} \mathrm{C}$

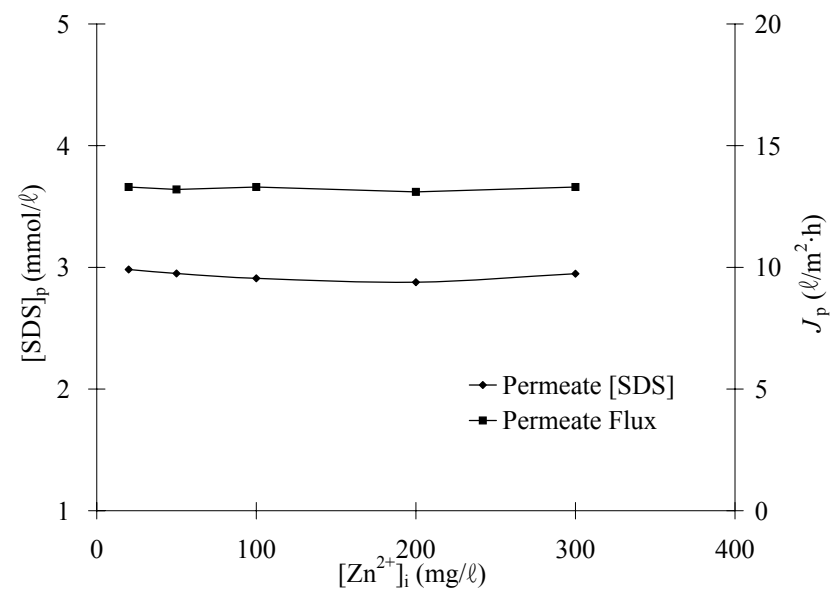

Figure 8

Effect of the initial $\mathrm{Zn}^{2+}$ concentration on the permeate SDS concentration and the permeate flux. $[S D S]_{i}=0.8 \times \mathrm{cmc}, \Delta P=0.07$ $M P a, T=30^{\circ} \mathrm{C}$

rejection was investigated at the initial SDS concentration constant equal to $0.8 \times \mathrm{cmc}$ and a constant pressure of $0.07 \mathrm{MPa}$. According to Fig. 7, along with the increase of the initial $\mathrm{Zn}^{2+}$ concentration, the $\mathrm{Zn}^{2+}$ rejection decreased gradually and the permeate $\mathrm{Zn}^{2+}$ concentration increased synchronously. The $\mathrm{Zn}^{2+}$ rejection decreased from $98 \%$ to $69.8 \%$ with the initial $\mathrm{Zn}^{2+}$ concentration ranging from $20 \mathrm{mg} / \ell$ up to $300 \mathrm{mg} / \ell$. This is because the initial SDS concentration was held constant at $0.8 \times \mathrm{cmc}$. When the initial SDS concentration is constant, the amount of micelles produced by concentration polarisation is approximately constant with the initial $\mathrm{Zn}^{2+}$ concentration ranging from $20 \mathrm{mg} / \ell$ up to $300 \mathrm{mg} / \ell$. Therefore the amount of adsorption site afforded by the micelles is limited. Along with the increase of the initial $\mathrm{Zn}^{2+}$ concentration, large numbers of the adsorption sites are occupied by the $\mathrm{Zn}^{2+}$ ions, and the amount of the adsorption sites decreases synchronously. Therefore, a large number of un-adsorbed $\mathrm{Zn}^{2+}$ ions pass through the membrane into the permeate solution.

The efficient removal of $\mathrm{Zn}^{2+}$ at low $\mathrm{Zn}^{2+}$ feed concentrations is a very important feature of MEUF. As observed from Fig. 7, the $\mathrm{Zn}^{2+}$ rejection was $98 \%$ when the initial $\mathrm{Zn}^{2+}$ concentration was equal to $20 \mathrm{mg} / \ell$. Other metal clean-up methods, such as

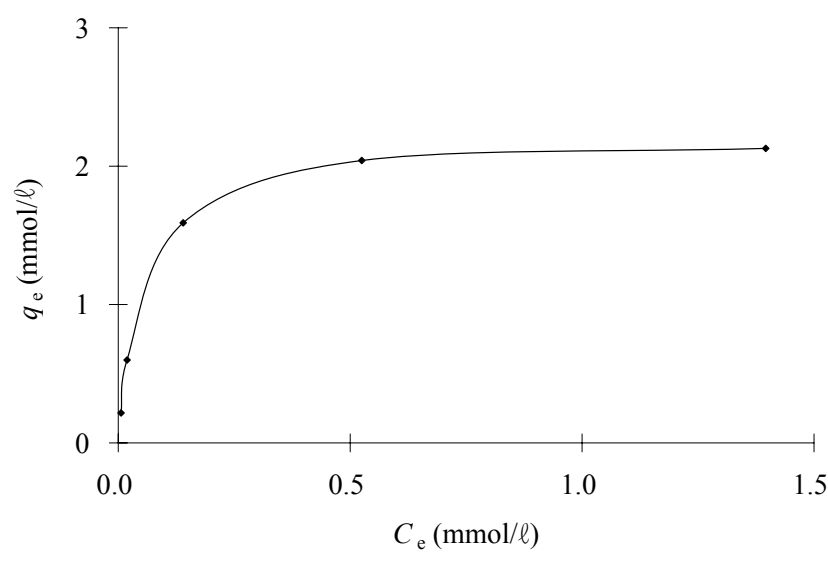

Figure 9

Isotherm of $\mathrm{Zn}^{2+}$ adsorption to the SDS micelle at $30^{\circ} \mathrm{C}$

precipitation by $\mathrm{pH}$ adjustment, show a decrease in efficiency as the metal solution is diluted. On the contrary, MEUF exhibits an increase in efficiency upon dilution.

\section{Effect of the $\mathrm{Zn}^{2+}$ concentration on the permeate SDS concentration and the permeate flux}

Figure 8 shows the variation of the permeate SDS concentration and the permeate flux with the initial $\mathrm{Zn}^{2+}$ concentration ranging from $20 \mathrm{mg} / \ell$ up to $300 \mathrm{mg} / \ell$ at the initial SDS concentration of $0.8 \times \mathrm{cmc}$ and a constant pressure of $0.07 \mathrm{MPa}$. Both the permeate flux and the permeate SDS concentration remained constant with the initial $\mathrm{Zn}^{2+}$ concentration varying. This is because the initial SDS concentration was held constant at $0.8 \times \mathrm{cmc}$. The permeate SDS concentration and the permeate flux are independent of the initial $\mathrm{Zn}^{2+}$ concentration.

\section{Adsorption isotherm}

The $\mathrm{Zn}^{2+}$ adsorption isotherm to the SDS micelle was established to investigate the characteristics of $\mathrm{Zn}^{2+}$ adsorption to the SDS micelle (Fig. 9). The adsorption isotherm revealed that $\mathrm{Zn}^{2+}$ adsorption increased with increasing $\mathrm{Zn}^{2+}$ concentration in the bulk liquid phase. At the equilibrium point of the isotherm, however, the amount of adsorbed $\mathrm{Zn}^{2+}$ remained constant along with the increase of the $\mathrm{Zn}^{2+}$ concentration. This phenomenon can be compared to the Langmuir adsorption isotherm model. The Langmuir adsorption isotherm equation is expressed by the following equation (Stumm and Morgan, 1996):

$$
q_{\mathrm{e}}=\frac{K q_{\max } C_{\mathrm{e}}}{1+K C_{\mathrm{e}}}
$$
where:

$K$ is the equilibrium adsorption constant $(\ell / \mathrm{mmol})$

$q_{\max }$ is the maximum amount of adsorbed $\mathrm{Zn}^{2+}$ ion (mmol/g)

$q_{\mathrm{e}}$ is the amount of adsorbed $\mathrm{Zn}^{2+}$ ion at equilibrium $(\mathrm{mmol} / \mathrm{g})$

$C_{\mathrm{e}}$ is the molar concentration of $\mathrm{Zn}^{2+}$ ion in the bulk liquid phase at equilibrium $(\mathrm{mmol} / \ell)$.

The value of $C_{\mathrm{e}}$ can be determined by the permeate $\mathrm{Zn}^{2+}$ concentration. Based on the mass balance, the amount of $\mathrm{Zn}^{2+}$ adsorbed at equilibrium $q_{\mathrm{e}}$ is calculated.

The rearrangement of Eq. (7) is given by the following equation: 


$$
\frac{1}{q_{\mathrm{e}}}=\frac{1}{q_{\max } K} \times \frac{1}{C_{\mathrm{e}}}+\frac{1}{q_{\max }}
$$

The linear relationship between $\left(1 / q_{\mathrm{e}}\right)$ and $\left(1 / C_{\mathrm{e}}\right)$ can be shown in Eq. (8). A linear plot of $\left(1 / q_{\mathrm{e}}\right)$ against $\left(1 / C_{\mathrm{e}}\right)$ was employed to give the values of $K$ and $q_{\max }$ from the slope and intercept of the plot (Fig. 10). According to Fig. 10, the Langmuir parameters together with the correlation coefficient $r^{2}$ are calculated. The equilibrium adsorption constant $K$ and the maximum amount of adsorbed $\mathrm{Zn}^{2+}$ ion $q_{\max }$ are equal to $17.2 \mathrm{\ell} / \mathrm{mmol}$ and 2.326 mmol-Zn ${ }^{2+}$ per g-SDS $(151 \mathrm{mg} / \mathrm{g})$, respectively. The correlation coefficient $r^{2}$ is equal to 0.999 . These parameters show that the Langmuir equation fits the $\mathrm{Zn}^{2+}$ adsorption isotherm to the SDS micelle well. The Langmuir equation of the $\mathrm{Zn}^{2+}$ adsorption to the SDS micelle can be obtained:

$$
q_{\mathrm{e}}=\frac{40 C_{\mathrm{e}}}{1+17.2 C_{\mathrm{e}}}
$$

\section{Conclusions}

The removal of $\mathrm{Zn}^{2+}$ ions from aqueous solutions by MEUF using single anionic surfactant sodium dodecyl sulphate (SDS) at low concentrations was investigated. When the initial SDS concentration was below the $\mathrm{cmc}(0.8 \times \mathrm{cmc})$ unexpectedly high $\mathrm{Zn}^{2+}$ rejection (97.5\%) was obtained due to concentration polarisation occurring near the membrane-solution interface.

The true rejection of the solute is no longer a function of the initial SDS concentration in the bulk solution but a function of the SDS concentration at the concentration polarisation layer. Although the permeate flux decreased with the increase of the initial SDS concentration due to the concentration polarisation, the permeate flux of $13.2 \mathrm{l} / \mathrm{m}^{2} \cdot \mathrm{h}$ was comparatively high when the initial SDS concentration was equal to $0.8 \times \mathrm{cmc}$. The permeate SDS concentration increased with initial SDS concentration. Whatever the concentration of surfactant in the feed is, the surfactant concentration in the permeate is lower than the cmc. In order to reduce surfactant dosage and surfactant loss, a good choice for initial surfactant SDS concentration is $0.8 \times \mathrm{cmc}(6.24$ mmol). The removal of $\mathrm{Zn}^{2+}$ at low $\mathrm{Zn}^{2+}$ feed concentrations is very efficient.

The characteristics of $\mathrm{Zn}^{2+}$ ion adsorption to surfactant micelle were represented by the Langmuir isotherm model. The equilibrium adsorption constant $K$ and the maximum amount of adsorbed $\mathrm{Zn}^{2+}$ ion $q_{\max }$ are equal to $17.2 \mathrm{\ell} / \mathrm{mmol}$ and $2.326 \mathrm{mmol} / \mathrm{g}$ $(151 \mathrm{mg} / \mathrm{g})$, respectively. The Langmuir isotherm model is effective for better understanding the mechanism of $\mathrm{Zn}^{2+}$ adsorption to the SDS micelle and also provides a theoretical tool needed for the MEUF technique application and optimisation.

These results demonstrate the potential practicality of the MEUF technique for removal of heavy metal ion pollutants such as $\mathrm{Zn}^{2+}$ at low surfactant concentrations and provide the scientific and technical basis for the application of the MEUF technique in practice. In the future, MEUF will be used widely to treat wastewaters containing heavy metal ions.

Further studies are indicated for the mechanism influencing concentration polarisation on the rejection of metal ions and permeation flux. The characteristics of metal ion adsorption to surfactant micelles and recovery of surfactant and metal ions also require further studies.

\section{Acknowledgements}

This study was financially supported by the National 863 High Technology Research Program of China (2004AA649370),

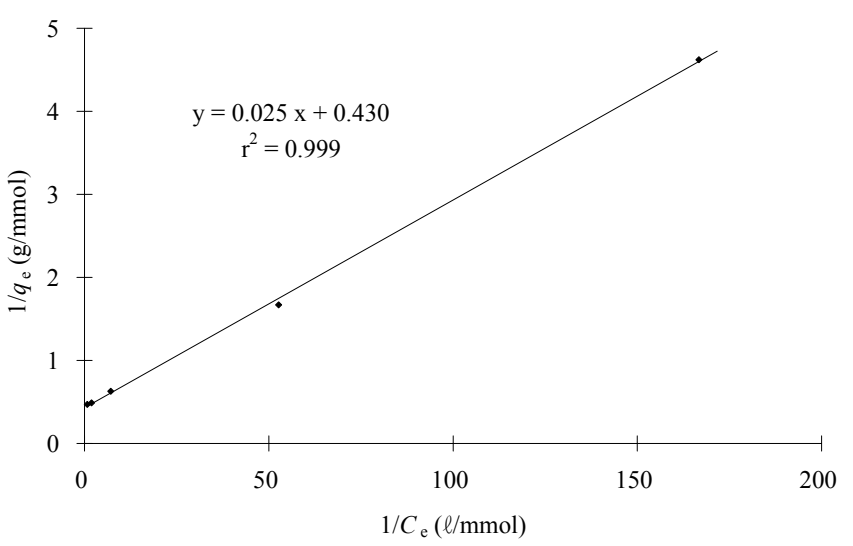

Figure 10

Linear regression of the $\mathrm{Zn}^{2+}$ adsorption to the SDS micelle at $30^{\circ} \mathrm{C}$

the National Basic Research Program (973 Program) (2005CB724203), the National Science Foundation of China (50608028), the National Foundation for Distinguished Young Scholars (50225926, 50425927), the Doctoral Foundation of Ministry of Education of China (20020532017), the Scientific Research Fund of Hunan Provincial Education Department ([2005]100) and the Teaching and Research Award Program for Outstanding Youth Teachers in Higher Education Institutions of MOE, P.R.C. (TRAPOYT) in 2000.

\section{References}

AHMADI S, HUANG YC, BATCHELOR B and KOSEOGLU SS (1995) Binding of heavy metals to derivatives of cholesterol and sodium dodecyl sulphate. J. Environ. Eng. ASCE 121 (9) 645652 .

AOUDIA M, ALLAL N, DJENNET A and TOUMIB L (2003) Dynamic micellar enhanced ultrafiltration: use of anionic (SDS)non-ionic(NPE) system to remove $\mathrm{Cr}^{3+}$ at low surfactant concentration. J. Membr. Sci. 217 (1-2) 181-192.

BAEK K, KIM BK, CHO HJ and YANG JW (2003) Removal characteristics of anionic metals by micellar-enhanced ultrafiltration. J. Hazard. Mater. 99 (3) 303-311.

BAEK K and YANG JW (2004) Cross-flow micellar-enhanced ultrafiltration for removal of nitrate and chromate: competitive binding. J. Hazard. Mater. 108 (1-2) 119-123.

FILLIPI BR, BRANT LW, SCAMEHORN JF and CHRISTIAN SD (1999) Use of micellar-enhanced ultrafiltration at low surfactant concentrations and with anionic-nonionic surfactant mixtures. J. Colloid Interface Sci. 213 (1) 68-80.

GZARA L and DHAHBI M (2001) Removal of chromate anions by micellar-enhanced ultrafiltration using cationic surfactants. Desalination 137 (1-2) 241-250.

GZARA L, HAFIANE A and DHAHBI M (2000) Removal of divalent lead cation from aqueous streams using micellar-enhanced ultrafiltration. Rev. Sci. Eau. 13 (3) 289-304.

JUANG RS, XU YY and CHEN CL (2003) Separation and removal of metal ions from dilute solutions using micellar-enhanced ultrafiltration. J. Membr. Sci. 218 (1-2) 257-267.

KIM J, KIM C, KIM D, KIM S, PARK S, LEE M and LIM J (2003) Removal of aromatic organics in aqueous solution via micellarenhanced ultrafiltration. Sep. Sci. Technol. 38 (8) 1791-1811.

LIU CK and LI CW (2004) Simultaneous recovery of copper and surfactant by an electrolytic process from synthetic solution prepared to simulate a concentrate waste stream of a micellar-enhanced ultrafiltration process. Desalination 169 (2) 185-192.

LIU CK, LI CW and LIN CY (2004) Micellar-enhanced ultrafiltration process (MEUF) for removing copper from synthetic wastewater containing ligands. Chemosphere. 57 (7) 629-634. 
LI CW, LIU CK and YEN WS (2006) Micellar-enhanced ultrafiltration (MEUF) with mixed surfactants for removing $\mathrm{Cu}$ (II) ions. Chemosphere 63 (2) 353-358.

SADAOUI Z, AZOUG C, CHARBIT G and CHARBIT F (1998) Surfactants for separation processes: enhanced ultrafiltration. J. Environ. Eng. ASCE 124 (8) 695-700.

STUMM W and MORGAN JJ (1996) Aquatic Chemistry: Chemical Equilibria and Rates in Natural Waters. Wiley Interscience Publication, New York. 521-531.
TUNG CC, YANG YM, CHANG CH and MAA JR (2002) Removal of copper ions and dissolved phenol from water using micellarenhanced ultrafiltration with mixed surfactants. Waste. Manage. 22 (7) 695701.

YURLOVA L, KRYVORUCHKO A and KORNILOVICH B (2002) Removal of $\mathrm{Ni}(\mathrm{II})$ ions from wastewater by micellar-enhanced ultrafiltration. Desalination 144 (13) 255260. 